\title{
Nucleolar organiser regions (AgNORS) in anal intraepithelial neoplasia and invasive anal squamous cell carcinoma
}

\author{
O A Ogunbiyi, J H Scholefield, F Sharp, R Ginsberg, K Rogers
}

\begin{abstract}
Aim: To evaluate the usefulness of counting nucleolar organiser region associated proteins (AgNORs) in the management of anal squamous neoplasia.

Method: Using a silver staining technique for NOR associated proteins, 32 routinely processed paraffin wax embedded sections of anal epithelium were assessed. These consisted of normal anal epithelium $(n=9)$, anal intraepithelial neoplasia (AIN) grades I $(n=5)$, and III $(n=13)$, and invasive squamous neoplasia of the anus $(\mathrm{n}=5)$.

Results: The median AgNOR counts for every 100 cells are as follows: normal anal epithelium 2.15 (95\% CI 1.89-3.94); AIN I 3.21 (95\% CI 2.89-7.14); AIN III $4 \cdot 32$ (95\%

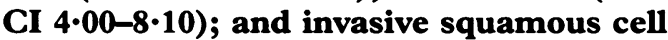
carcinoma of the anus $5.51 \quad(95 \%$ CI 2-48-10-62). There were significant differences between AgNOR counts in anal cancer and normal epithelium ( $<<0.05$; Mann-Whitney U test)), AIN III and normal anal epithelium $(p<0.005)$, and AIN III and AIN I (p < 0.05). No significant differences were observed between AIN I and normal anal epithelium, anal cancer and AIN I, and anal cancer and AIN III. There was a considerable degree of overlap among the different groups.

Conclusions: Despite the strong association between AgNOR values and degree of dysplasia, the variability within pathological grade may preclude the adoption of this technique on its own as a prognostic indicator. It may, however, be useful in conjunction with other markers of neoplastic growth such as c-myc oncogene amplification or overexpression as a marker of disease progression in AIN and invasive anal squamous cell cancer.
\end{abstract}

(F Clin Pathol 1992;45:889-893)

Department of Surgery, Clinical Sciences Centre, Northern General Hospital, Sheffield S5 7AU

O A Ogunbiyi

J H Scholefield

K Rogers

Department of

Obstetrics and

Gynaecology

F Sharp

R Ginsberg

Correspondence to: Mr O A Ogunbiyi

Accepted for publication 6 April 1992

Squamous cell carcinoma of the anus is an uncommon tumour, comprising $3 \%$ of large bowel tumours. ' However, in some groups such as immunosuppressed organ transplant recipients, homosexual men who practise receptive anal intercourse, and in group IV (Centers for Disease Control) HIV seropositive persons, the incidence of squamous anal cancer is increasing. ${ }^{24}$ Anal intraepithelial neoplasia (AIN), which was first described by Fenger and Nielsen in $1981^{5}$ and which was thought initially to be rare, has also been shown to be increasing in prevalence in the above groups. ${ }^{4-6}$ Although the prevalence and clinical importance of AIN remains unknown, it has been suggested that there may be a possible parallel between AIN and cervical intraepithelial neoplasia (CIN) as regards progression to invasive squamous cancer. If this is true, the availability of a marker identifying those AIN lesions most likely to progress to invasive cancer would be extremely useful in the management of patients who are thought to be at risk.

Nucleolar organiser regions (NORs) are loops of ribosomal DNA (rDNA) occurring in the nucleoli of cells, which transcribe to ribosomal RNA (rRNA) and ultimately direct ribosome and protein formation. ${ }^{7}$ Because of the close association between NORs and cell activity, their number or size is thought to reflect cell proliferation, transformation, and even malignancy. NORs are readily identified by means of the silver binding (argyrophillia) of their associated proteins-the AgNOR technique. ${ }^{8}$ The method has permitted the recognition of NORs in chromosome spreads, whole cells, and histological sections. Using the AgNOR technique on routinely processed paraffin wax embedded tissue, there have been reports that it is useful in discriminating between benign melanonaevi and malignant melanoma, ${ }^{9}$ Spitz and pigmented spindle cell naevi from melanoma, ${ }^{10}$ and between low and high grade lymphomas. ${ }^{11}$ Significant differences in the AgNOR counts of the different grades of CIN have been shown recently, ${ }^{12}$ although the degree of overlap between the grades limits the use of this method in the diagnosis.

This study is, to our knowledge, the first systematic study of AgNORs in AIN and invasive anal cancer. Using a silver staining technique for NOR associated proteins, we have attempted to identify a marker which could be useful in the identification of patients with AIN at risk of progression to invasive anal cancer, and hence their subsequent management.

\section{Methods}

Thirty two anal epithelial specimens were studied. These comprised: nine normal anal epithelium, five AIN I, 13 AIN III and five squamous cancers. These were taken from the archival files of the Histopathology Department at the Northern General Hospital, Sheffield. The histology on all specimens was reviewed by one consultant pathologist with an 

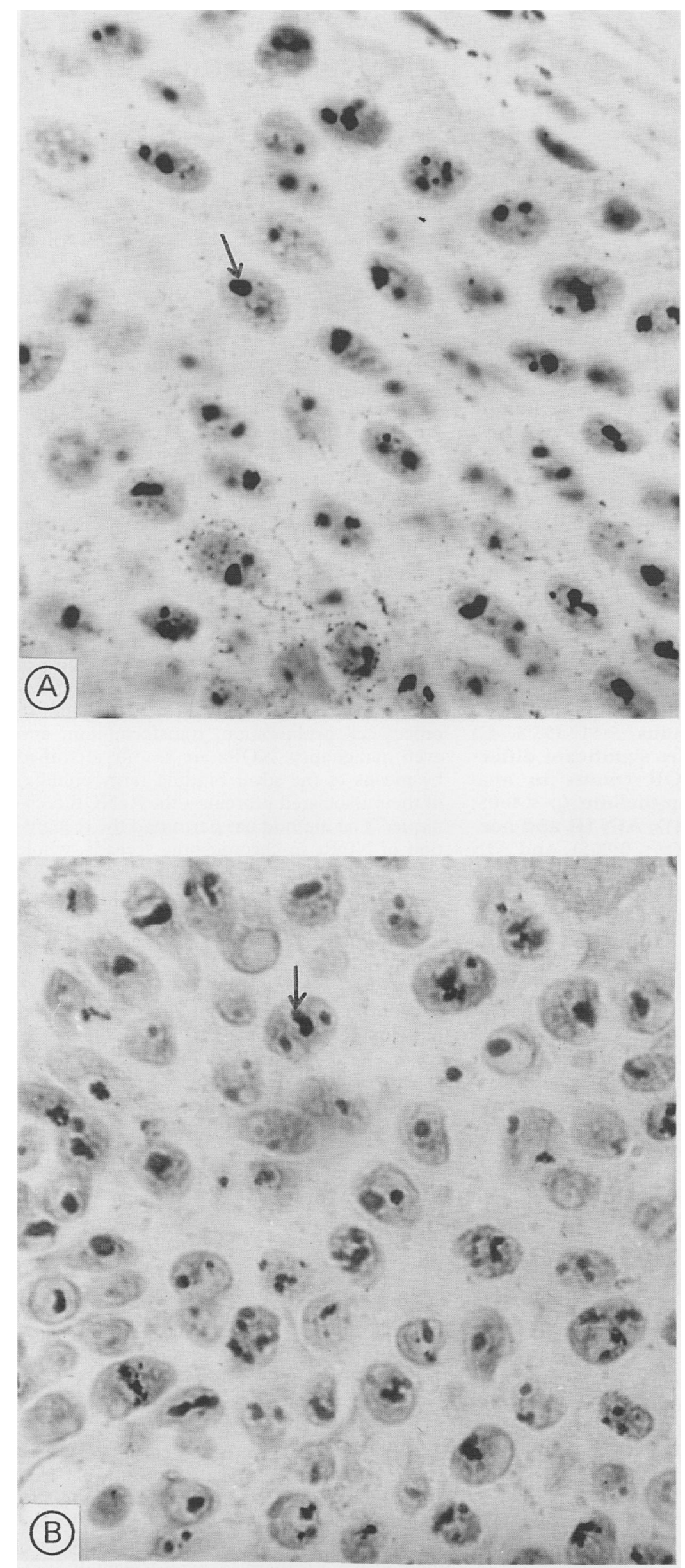

Figure 1 AgNORs in (A) normal anal epithelium and (B) AIN I. The AgNORs show up as single or multiple black dots in the nucleus (shown by arrows). interest in anogenital neoplasia. The specimens had been fixed in $10 \%$ buffered formalinphosphate and paraffin wax embedded. Sections ( $5 \mu \mathrm{m}$ thick) were dewaxed in xylene and hydrated through graded ethanols to deionised water. Adjacent sections from each block were stained with haematoxylin and eosin and for silver binding NOR associated protein, as described by Smith and Crocker. ${ }^{13}$ The AgNOR staining solution was prepared by dissolving a $2 \%$ solution of gelatin in $1 \%$ formic acid. This solution was then mixed in a ratio of $1: 2$ with $50 \%$ aqueous silver nitrate. The tissue sections were immersed in the final working solution and left for 30 minutes at room temperature in a dark room. The slides were then fixed, washed in distilled water, dehydrated in ascending grades of ethanol and mounted. The presence of NORs is indicated by the appearance of black silver granule(s) in the nucleus (fig 1).

AgNORs present in the nuclei of 100 consecutive normal or atypical anal epithelial cells were counted at a magnification of $\times 100$ using an oil immersion lens by a single observer. Two methods of AgNOR enumeration were evaluated by two observers in a preliminary series of 10 specimens. In the first method the actual numbers of AgNORs were quantified by counting each apparent dot even when they touched or overlapped. The interobserver variation was $25-30 \%$ using this method. The second method involved counting the number of separable black dots in each nucleus. Overlapping dots were counted as one. Using this method, interobserver variation was $5-8 \%$. The second method of AgNOR enumeration was therefore felt to be more reliable and used for the purpose of this study. The number of nuclei to be counted in each specimen was determined by the cumulative means technique. Using this procedure, it was shown that the mean number of AgNORs would not have been altered in any lesion by counting more than 100 nuclei.

All the data were analysed using the MannWhitney $U$ test for non-parametric data.

\section{Results}

For each specimen, the cumulative means technique was used to determine the number of nuclei that needed to be counted before the means became stable. The mean was arbitrarily defined as being stable when the mean reached and stayed within $\pm 5 \%$ of the final mean ( $n=$ 100). Figure 2 illustrates moving average plots of typical examples of normal anal epithelium, AIN III, and invasive squamous carcinoma of the anus. In the illustrated examples the mean values became stable after 30 nuclei had been counted for normal anal epithelium and 50 nuclei for both AIN3 and anal squamous cancer. The median numbers of nuclei counted in each group before the mean became stable are as follows: normal anal epithelium $(n=9)$ 35 (range 20-70); AIN I $(n=5) 40$ (range 30-70); AIN III ( $n=13$ ) 50 (range 30-70); and invasive anal squamous cell carcinoma (n = 5) 50 (range 20-70). 

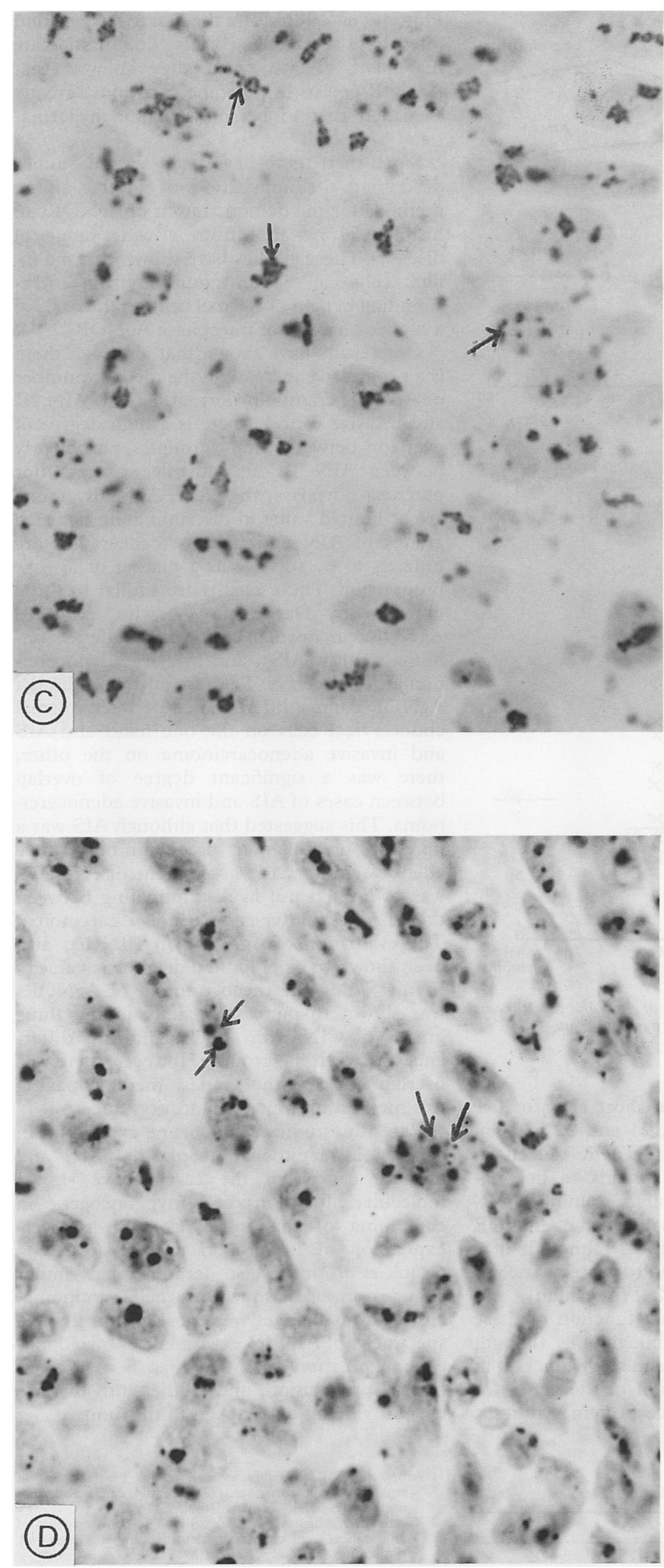

Figure 1 continued AgNORs in (C) AIN III and (D) invasive anal squamous carcinoma. The AgNORs show up as single or multiple black dots in the nucleus (shown by arrows). The dots in AIN III and anal cancer are smaller and form numerous clusters compared with normal anal epithelium and AIN $I$.
The scattergram in fig 3 depicts the mean AgNOR counts for each specimen in all four diagnostic groups. In all specimens AgNORs were clearly visible as black dots of varying sizes in the nuclei. These were arranged into one or more clusters or as individual satellites-extranuceolar. In AIN III and invasive anal squamous cancer specimens there were more AgNOR clusters as well as extranucleolar AgNORs present compared with normal anal epithelium and AIN I. The final median values for each group are shown in table 1. Although there is a progressive increase in the median AgNOR values, there is a considerable degree of overlap between the four groups as illustrated in the scattergram. Using the MannWhitney $U$ test for non-parametric data (table 2), there were significant differences between AgNOR counts in anal cancer and normal anal epithelium ( $p<0.05)$, AIN III and normal anal epithelium ( $<<0.005)$, and AIN III and AIN I $(p<0.05)$. No significant differences were observed between AIN I and normal anal epithelium, anal cancer and AIN I, and cancer and AIN III.

\section{Discussion}

Although possible parallels between AIN and CIN have been suggested, ${ }^{6}$ the natural history of AIN is still unknown. However, AIN III has been detected in resection specimens for squamous anal cancer. ${ }^{414}$ These lesions were usually found adjacent to the tumours as well as in areas separated from the tumour by normal mucosa. AIN seems to be fairly common in certain at risk groups, and in view of the rarity of anal carcinoma (3\% of bowel cancers), most of the AIN lesions seem to regress or remain static. This poses problems in the management of AIN lesions, as treating all lesions would result in unnecessary treatment of large numbers of patients. On the other hand, the possibility that a small number of patients with untreated AIN may progress to invasive cancer has to be considered. How, then, do we determine which AIN lesions are likely to progress to invasive cancer? Ideally a marker identifying abnormal anal cells would aid in the diagnosis and follow up of patients with AIN.

This study gives the first description of AgNOR counts in AIN and invasive anal squamous cancer. We have tried to evaluate the usefulness of AgNORs in differentiating between anal neoplastic lesions and hence the possibility of using the method as a marker in following the progress of AIN lesions. The AgNOR technique has been used by cytogeneticists for over a decade, although it has only recently been applied in histopathology. ${ }^{11}$ The

Table 1 Median AgNOR values

\begin{tabular}{lll}
\hline & Median & CI \\
\hline Normal & $2 \cdot 15$ & $95 \%(1 \cdot 89-3 \cdot 94)$ \\
AIN I & $3 \cdot 21$ & $95 \%(2 \cdot 89-7 \cdot 14)$ \\
AIN III & $4 \cdot 32$ & $95 \%(4 \cdot 00-8 \cdot 10)$ \\
Carcinoma & $5 \cdot 51$ & $95 \%(2 \cdot 48-10 \cdot 62)$ \\
\hline
\end{tabular}




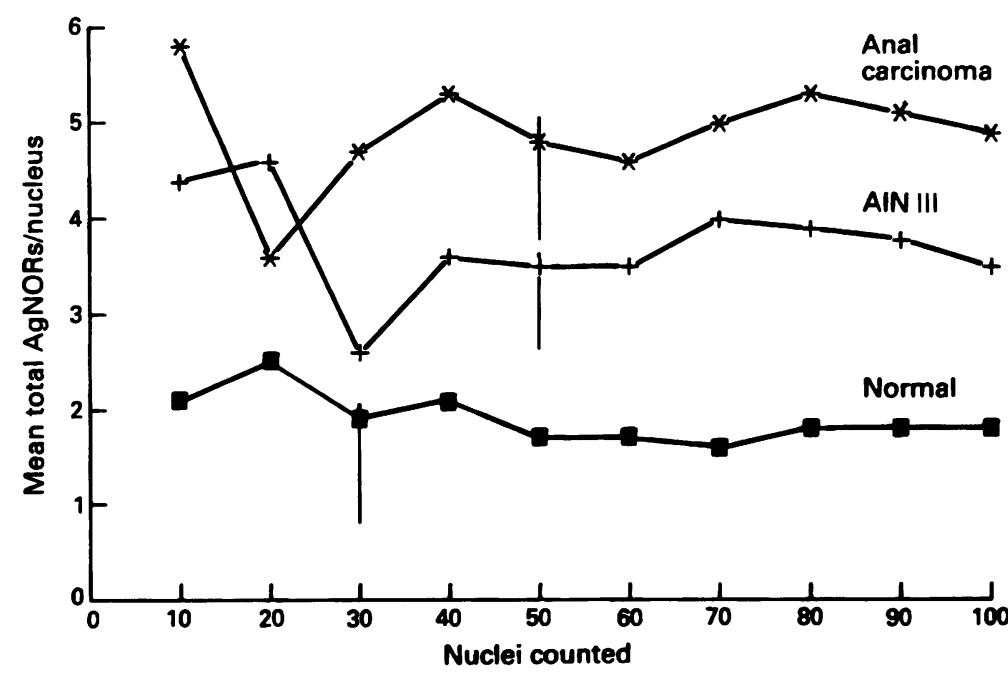

Figure 2 Cumulative means technique: moving average plots of typical examples of normal anal epithelium, AIN III and invasive anal squamous cell carcinoma. The vertical bars indicate the number of nuclei counted to achieve a stable mean.

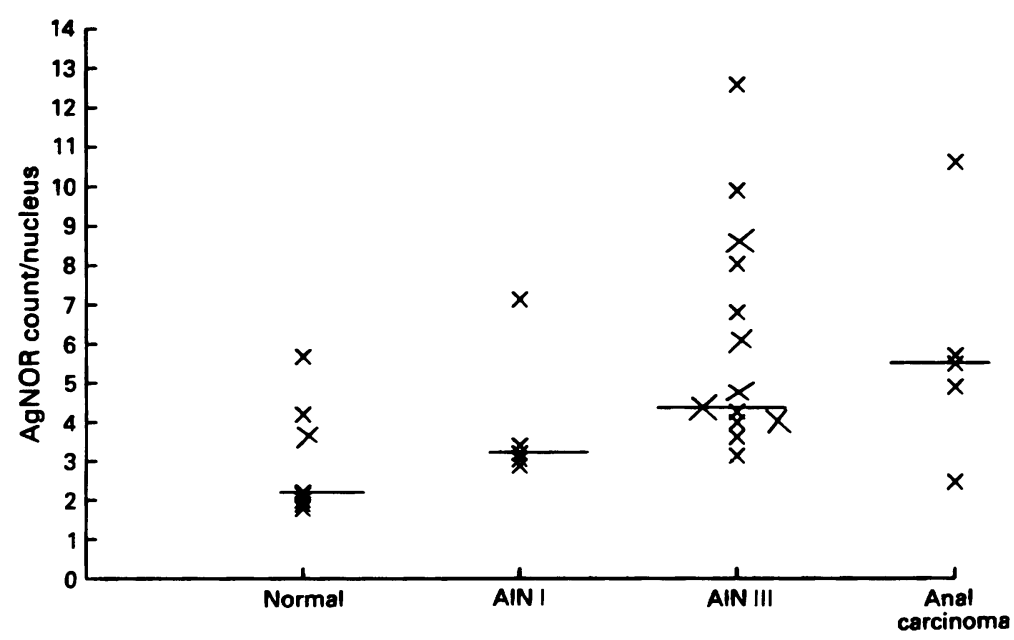

Figure 3 Scattergram to show the distribution of total numbers of AgNORs per 100 cells of each case examined. The horizontal bars indicate the median for each group.

NORs are present on the short arms of five chromosomes 13, 14, 15, 21 and 22 in man, and have allowed various genetic defects in metaphase chromosome spreads to be analysed. The nature of the silver staining NORassociated proteins shown by the AgNOR technique is not fully known, although it is thought they may be related to proteins such as RNA polymerase $\mathrm{I}^{15} \mathrm{C} 23$ (nucleolin), and B23 protein. ${ }^{1617}$ The exact function of these proteins is uncertain, although it is thought that they may have some regulatory function in controlling the transcription of the genes for ribosomal RNA and hence protein synthesis.
Ploton et al (1986) were the first to suggest that interphase AgNOR counts could indicate malignant disease when they showed that AgNOR counts in prostatic carcinoma greatly exceeded that in benign prostatic hyperplasia. ${ }^{18}$

Since then there have been several studies describing the application of silver staining methods for the demonstration of AgNORs in histological material from a wide range of diseases. These studies have shown that malignant cells can be distinguished from corresponding benign or normal cells on the basis of a higher quantity of interphase AgNORs. ${ }^{19} 20$

Our results have shown that although there is a progressive increase in the median number of AgNOR counts in normal, AIN I, AIN III and invasive cancer, there is a high degree of overlap between the groups, particularly between AIN III and invasive cancer. For practical purposes, therefore, AgNOR counts are of limited value in discriminating between grades of AIN and invasive cancer and are unlikely to be suitable as a marker of disease progression. These results are similar to those obtained by Darne et $a l,^{21}$ who evaluated AgNORs in normal endocervix, adenocarcinoma in situ (AIS), and invasive adenocarcinoma of the cervix. They found that although AgNOR counts differentiated between normal endocervical cells on the one hand and AIS and invasive adenocarcinoma on the other, there was a significant degree of overlap between cases of AIS and invasive adenocarcinoma. This suggested that although AIS was a potential premalignant precursor of invasive adenocarcinoma, the assessment of AgNORs was of limited use in discriminating between the histological types of cervical carcinoma. The evaluation of AgNORs in CIN has also been shown to be of limited diagnostic value. ${ }^{12}$ In that study the mean number of AgNORs was shown to increase steadily in the three grades of CIN with some significant differences between the groups. However, there was overlap between the grades, thereby making this method of limited dignostic value.

Recently, studies of oncogene expression in cervical intraepithelial neoplasia (CIN) and invasive cancer of the cervix have shown molecular alterations of c-myc oncogene in carcinoma of the cervix as well as overexpression of its protein product p62..$^{23}$ Crook et $a l^{24}$ have also demonstrated similar changes in anal squamous cell carcinoma, although no changes were observed in the five specimens of AIN III examined. C-myc oncogene expression may serve as a marker of disease progression, and studies into this are currently being undertaken in this unit.
Table 2 Statistical analysis of AgNOR counts using Mann-Whitney $U$ test

\begin{tabular}{llll}
\hline & Point estimate & CI & $P$ value \\
\hline Normal $v$ AIN I & $-1 \cdot 10$ & $95(-2.941,0.931)$ & $>0.05$ \\
Normal $v$ AIN III & -2.270 & $95(-5.701,-1.350)$ & $<0.005$ \\
Normal $v$ anal carcinoma & -3.130 & $95(-6.419,-0.329)$ & $<0.05$ \\
AIN I $v$ AIN III & -1.110 & $95(-5.399,-0.220)$ & $<0.05$ \\
AIN $v$ anal carcinoma & -2.110 & $95(-7.410,1.632)$ & $>0.05$ \\
AIN III $v$ anal carcinoma & -0.600 & $95(-2.098,3.679)$ & $>0.05$ \\
\hline
\end{tabular}

1 Morson BC. The pathology and results of treatment of squamous cell carcinoma of the anal canal and anal margin. Proc Roy Soc Med 1960;53:416-20.

2 Wexner SD, Milsom JW, Dailey TH. The demographics of anal cancers are changing: Identification of a high risk population. Dis Colon Rectum 1987;30:942-6.

population. Dis Colon Rectum 1987;30:942-6.
3 Penn I. Cancers of the anogenital region in renal transplant recipients. Analysis of 65 cases. Cancer 1986;58:611-16. recipients. Analysis of 65 cases. Cancer 1986;58:611-16. Palefsky JM, Gonzales J, Greenblatt RM, Ahn DK, Hollander $\mathrm{H}$. Anal intraepithelial neoplasia and anal papilloIV HIV disease. $\mathcal{H} A M A$ 1990;263:2911-16. 
5 Fenger C, Nielsen VT. Dysplastic changes in the anal canal epithelium in minor surgical specimens. Acta Pathol Microbiol Scand 1981;89:463-5.

6 Scholefield JH, Sonnex C, Talbot IC, et al. Anal and cervical intraepithel

7 Alberts B, Bray J, Lewis J, Raff M, Roberts K, Watson JD. The cell nucleus. In: Molecular biology of the cell. New York: The cell Bucleus. In:

8 Goodpasture C, Bloom SE. Visualisation of nucleolar organizer regions in mammalian chromosomes using ilver stain

9 Crocker J, Skilbeck N. Nucleolar organiser region associated proteins in cutaneous melanotic lesions: a quantitative study. $\mathcal{F}$ Clin Pathol 1987;40:885-9.

10 Evans AT, Orrell JM, Grant A. Re-evaluating silver stained nucleolar organiser regions (AgNORs) in problematic cutaneous melanoeytic lesions: A study with quantitation and pattern anlaysis. F Pathol 1991;165:61-7.

11 Crocker J, Nar P. Nucleolar organiser regions in lymphomas. F Pathol 1987;151:111-18.

12 Egan M, Freeth M, Crocker J. Intraepithelial neoplasia, human papilloma virus infection and argyrophilic nucleohuman papilloma virus infection and argyrophilic nucleoprotein

13 Smith R, Crocker J. Evaluation of nucleolar organiser region associated proteins in breast malignancy. Histopathology 1988;12:113-25.

14 Fenger C, Nielsen V. Precancerous changes in the anal cana epithelium in resection specimens. Acta Pathol Microbio Scand 1986;94:63-9.

15 Williams MA, Kleinschmidt JA, Krohne G, Franke WW. Aroyrophilic nuclear and molecular proteins of Xenopus laevis odcytes identified by gel electrophoresis. Exp Cell
Res 1982;137:341-51

16 Lischwe MA, Smetana K, Olson MOJ, Busch H. Proteins $C_{23}$ and $B_{23}$ are the major nucleolar silver staining proteins. Life Sci 1979;25:701-8.

17 Olson MOJ, Thompson BA. Distribution of proteins among chromatin components of nucleoli. Biochemistry 1983;22:3187-93.

18 Ploton D, Menager M, Jeanneson P, Himber G, Pigeon F, Adnett JJ. Improvement in the staining and in the visualisation of the argyrophillic proteins of the nucleolar organiser region at the optical level. Histochem $\mathcal{f} 1986$; 18:5-14.

19 Quinn CM, Wright NA. The clinical assessment of proliferation and growth in human tumours: Evaluation of methods and applications as prognostic variables. $\mathcal{f}$ Pathol 1990;160:93-102.

20 Crocker J. Nucleolar organizer regions. In: Underwood JCE, ed. Current topics in pathology: Pathology of the nucleus. Berlin: Springer Verlag 1990:91-149.

21 Darne JF, Polacarz SV, Sheridan E, Anderson D, Ginsberg $R$, Sharp F. Nucleolar organiser regions in adenocarcinoma in situ and invasive adenocarcinoma of the cervix. Clin Pathol 1990;43:657-60.

22 Pinion SB, Kennedy JH, Miller RW, Maclean AB. Oncogene expression in cervical intraepithelial neoplasia and invasive cancer of cervix. Lancet 1991;337:819-20.

23 Ocadiz R, Sauceda R, Cruz M, Graef AM, Graniglio P. High correlation between molecular alterations of the c-myc oncogene and carcinoma of the uterine cervix. Cancer Res 1987;47:4173-7.

24 Crook T, Wrede D, Scholefield JH, Crawford L, Vousden $\mathrm{KH}$. Status of c-myc, $\mathrm{p} 53$ and retinoblastoma genes in human papillomavirus positive and negative cell carcinoma of the anus. Oncogene 1991;6:1251-7. 